Annals of Plant Sciences

ISSN: 2287-688X

OPEN ACCESS

Research Article

www.annalsofplantsciences.com

\title{
Notes on phytoplasma diseases from Dakshin Dinajpur district of West Bengal, India
}

Tapas K. Chakraborty

Department of Botany, Rishi Bankim Chandra College, P.O. Naihati, North 24 Parganas, West Bengal, Pin-743165, India.

Received: 2017-09-13; Accepted: 2017-11-12

\begin{abstract}
Phytoplasmas are pleomorphic prokaryotes located in the sieve elements of the phloem of different infected plant species. In this communication the author first time from West Bengal, India reports phytoplasmal diseases of four different plants (Datura stramonium, Ziriphus oenoplia, Catharanthus roseus and Solanum melongena) belong to different families based on symptoms and grafting experiments.
\end{abstract}

Keywords: Phytoplasma; phyllody; Dakshin Dinajpur; West Bengal; India

\section{Introduction}

Phytoplasmas, earlier known as mycoplasma like organisms (MLOs), were discovered by a group of Japanese Scientists (Doi et al., 1967). These are very small, wall-less, pleomorphic prokaryotes located in the sieve elements of the phloem of infected plant species. They severely affect herbaceous and woody plants exhibiting symptoms of virescence/ phyllody, sterility of flowers, witches' broom, abnormal and generalized stunting (Jung et al., 2012). Phytoplasma diseases are traditionally detected by studying the characteristic symptoms induced in the host plants. Molecular tools are now used to identify and differentiate phytoplasmas. Using the molecular techniques, different phytoplasmas have been characterized from as many as 45 plant species in India. Phytoplasma groups in India showed a wide geographical distribution especially in Northern and Southern parts of India (Mall et al., 2011, Rao et al., 2011). In this communication the author first time from West Bengal reports phytoplasmal diseases of four different species belonging to three different families.

In the present investigation on the occurrence of phytoplasmal diseases in plants of Dakshin Dinajpur district of West Bengal, India, the author observed phytoplasmal diseases in four different plant species, viz: Catharanthus roseus (L.) G. Don (Apocynaceae), Datura stramonium L. \& Solanum melongena L. (Solanaceae) and Ziriphus oenoplia (L.) Mill. (Rhamnaceae). Dakshin Dinajpur is located in between $26^{\circ} 35^{\prime} 15^{\prime \prime}$ and $26^{\circ} 10^{\prime} 15^{\prime \prime} \mathrm{N}$ latitude and $89^{\circ} 30^{\prime \prime}$ and $87^{\circ} 48^{\prime} 37^{\prime \prime} \mathrm{E}$ longitude and is situated in the northern part of West Bengal, India. The presence of phytoplasmas was diagnosed by studying the characteristic symptoms expressed on previously mentioned four different infected plant species (Figure 1). Symptoms of the disease appeared in the form of severe reduction in leaf size and shortening of internodes. These ultimately resulted in crowding of leaves on leaf bearing branches and generalized stunted growth in all the four plant species mentioned above. Phyllody was observed both in D. stramonium (Fig. 1a) and Z. oenoplia (Fig. 1b) and these plants never bloomed. Moreover, Z. oenoplia expressed witches' broom appearance by proliferation of axillary buds. Infected $C$. roseus plant produced very small flowers (Fig. 1c) and S. melongena plant produced very small fruits (Fig. 1d). Twigs from all the four diseased plants (scion) were wedge-grafted to mature healthy suitable host plants. Grafts were established successfully in $70-75 \%$ plants in D. stramonium, $Z$. oenoplia and $S$. melongena. Successful graft was not developed in C. roseus plant; this may be due to nonwoody habit of the plant. Disease symptoms appeared in all three hosts within 45-60 days after grafting. Since no report of phytoplasmal infection has been documented from the eastern part of India (Mall et al., 2011, Rao et al., 2011) thus this article for the first time reports phytoplasmal infection on the basis of symptoms on host plants as well as grafting experiments.

\footnotetext{
${ }^{*}$ Corresponding Author:

Dr. Tapas K. Chakraborty

Department of Botany, Rishi Bankim Chandra College,

P.O. Naihati, North 24 Parganas,

West Bengal, Pin-743165, India.

E-mail: tkchakraborty@yahoo.com
}

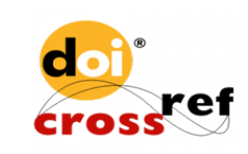

Page | 1866 
Figure 1: Phytoplasma infected plants showing characteristic symptoms.
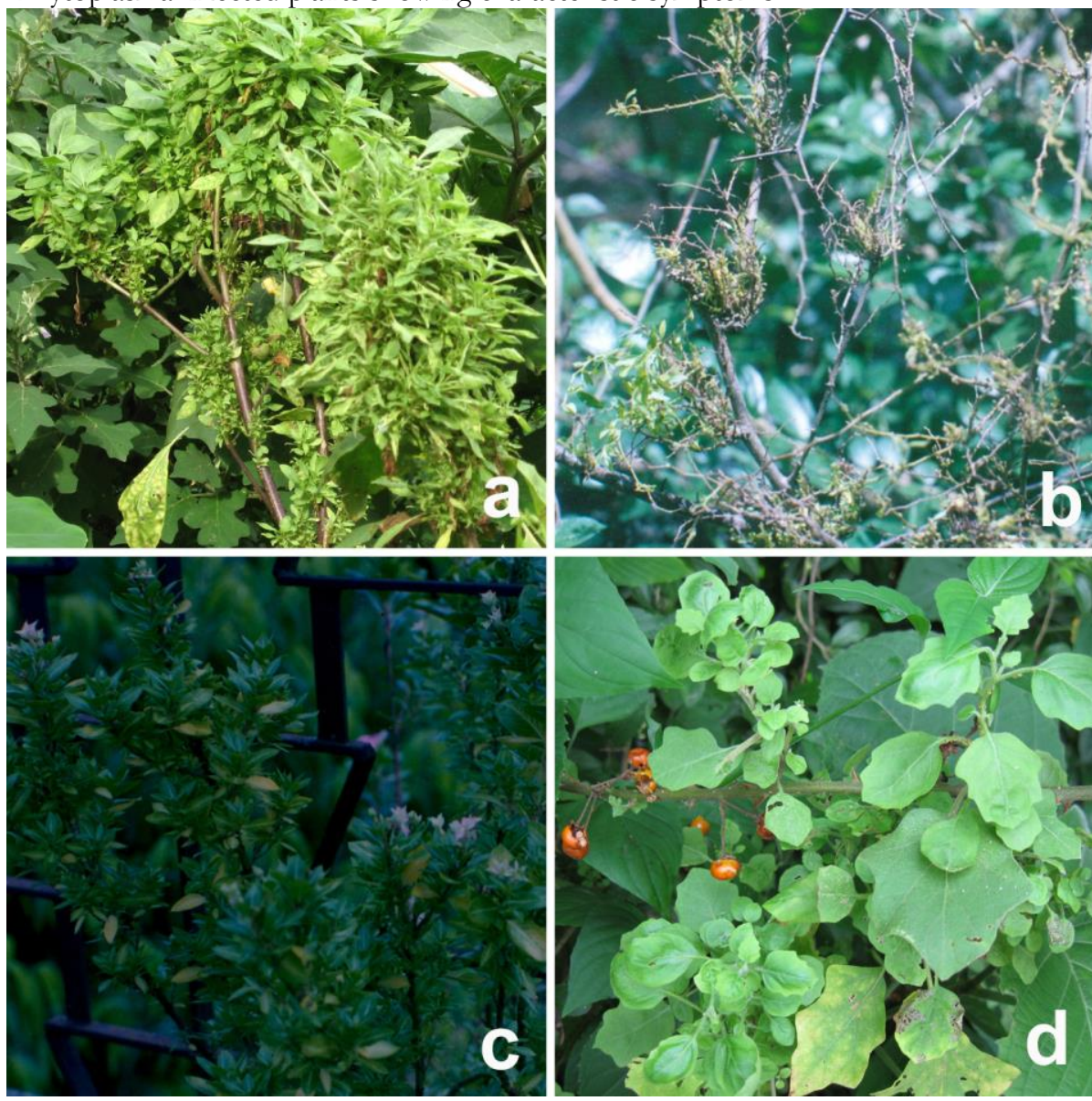

a) Datura stramonium, b) Ziziphus oenoplia, c) Catharanthus roseus d) Solanum melongena

\section{Acknowledgement}

The author is grateful to the Teacher-in-Charge, Balurghat College, Dakshin Dinajpur, West Bengal, India for providing the necessary laboratory facilities in the Department of Botany.

\section{References}

1. Doi $\mathrm{Y}, \mathrm{M}$ Teranaka, $\mathrm{K}$ Yora and $\mathrm{H}$ Asuyama. "Mycoplasma or PLT group-like microorganisms found in the phloem elements of plants infected with mulberry dwarf, potato witches' broom, aster yellows or paulownia witches' broom." Annals of the Phytopathological Society of Japan 33(1967): 259-266.

2. Jung HY, NW Kyu and YH Kim. "Current Status of Phytoplasmas and their Related Diseases in Korea." Plant Pathology Journal 28(2012): 239-247.
3. Mall S, Y Chaturvedi, GP Rao and VK Barnwal. "Phytoplasma's diversity in India." Bulletin of Insectology 64(Supplement)(2011): S77-S78.

4. Rao GP, S Mall, SK Raj and SK Snehi. "Phytoplasma disease affecting various plant species in India." Acta Phytopathologica et Entomologica Hungarica 46(2011): 59-99.

\section{Cite this article as:}

Tapas K. Chakraborty. Notes on phytoplasma diseases from Dakshin Dinajpur district of West Bengal, India. Annals of Plant Sciences 6.12 (2017) pp. 1866-1867.

doi: http://dx.doi.org/10.21746/aps.2017.6.12.8

Source of support: Nil

Conflict of interest: Nil 